(c) 2010 IEEE. Personal use of this material is permitted. Permission from IEEE must be obtained for all other uses, in any current or future media, including reprinting/republishing this material for advertising or promotional purposes, creating new collective works, for resale or redistribution to servers or lists, or reuse of any copyrighted component of this work in other works. 


\section{State of the Art: Carbon Emission Accountability Modeling}

\author{
Valencia Lo \\ Digital Ecosystems \& Business Intelligence Institute \\ Curtin University of Technology \\ Perth, Australia \\ e-mail: lovalencia@gmail.com
}

\author{
Vidyasagar Potdar \\ Digital Ecosystems \& Business Intelligence Institute \\ Curtin University of Technology \\ Perth, Australia \\ e-mail: Vidysagar.Potdar@cbs.curtin.edu.au
}

\begin{abstract}
Global warming is becoming a big problem and carbon emissions from a variety of sources are the cause of it. To control emission, a number of carbon emission reduction policies and schemes such as the Kyoto Protocol \& COP15 treaty have been reached and put in place. However, not all countries participate in these global carbon mitigation treaties. One of the many reasons for the absence of participation in developing countries is due to their incapable financial status. As in the case of developed countries such as the USA, it is usually due to monetary profiting before and after the participation and the ambiguous carbon emission responsibility that each country has to bear. Many accounting models have already been proposed in the current literature to solve the problem of responsibility ambiguity. However, the current accountability models are proposed for the general industries and not for the ICT industry. We feel that these models cannot be applied directly to the ICT industry since factors of influence are significantly different. In ICT industry, it involves a mix of international and national factors such as accountability issues (eg. the party responsible for the carbon emission) and the implications of participants and nonparticipants of those climate change mitigation treaties in different countries. Hence, taking into account all the determinant factors and different stakeholders involved in the process of the carbon accounting, we are proposing an efficacious and fair accountability model for the ICT industry in our research. This accountability model can be used to assist Government worldwide in coming up with a fair tax 'relief/subsidy' scheme for ICT companies for more sustainable business models. This research will take a science and engineering approach and the outcome of this research would be significant to the global combat against climate change.
\end{abstract}

Keywords-ICT industry; data centers; Internet servers; Climate change; Kyoto Protocol

\section{INTRODUCTION}

Recent researches on carbon emission have pointed out the significant and relentless contribution of greenhouse gas (GHG) emissions into the environment by date center running Internet servers. Data centers are a stew of nonhomogenous hardware technologies from many different manufacturers. Servers are an important component of total data center load, but so are mainframes, disk and tape storage, networking, and communications equipment. Consolidations of applications are likely to have played a significant role in reducing what otherwise would have been major additional growth in power consumption (Brill, K. G., 2007).

The growth of Internet is one of the causes of increased energy usage by servers and the infrastructure supporting them, thus making Internet data centers a major source of increases in energy consumption, particularly in the US. According to Scientists at Lawrence Berkeley National Laboratory, Websites and other servers consumed over 7 terawatt-hours (TWh) of electricity in the US in 1999, more than the Internet switching infrastructure itself. Although the actual figure is still not yet known, it is clear that Internet services are significant energy consumers in the US and globally (Chase, J. S. \& Doyle, R. P, n.d.).

According to Bryce's article in http://www.zdnet.com, these facilities have typical power densities of 100 watts per square foot for servers, storage, switches, and cooling, and could add $5 \mathrm{GW}$ of power demand, which is about $10 \%$ of the current generating capacity for California. It is forecasted in Chase \& Doyle (n.d.) that new data centers in Seattle area are to increase the city's power demands by $25 \%$.

All this electricity production and consumption could potentially harm the environment and power pricing in most countries has not yet factor in the environmental costs (Chase, J. S. \& Doyle, R. P., n.d.). Therefore, it is necessary to reduce power consumption and demand for Internet servers as a matter of professional and social responsibility aiding in the combat of climate change policies such as the Kyoto Protocol.

In 2000 , data centers consumed approximately $0.8 \%$ of total US electrical consumption; and in 2005, despite a $7 \%$ growth in electricity production, data center power consumption grew to consume approximately $1.4 \%$ of the total (Brill, K. G., 2007). In a study by Brill (2007), even after assumption that some utilization gains from virtualization and incremental improvements to server efficiency, data centers are still projected to consume $2.3 \%$ of the total electricity production by 2010 . Some reports have these estimates place even higher (Brill, K. G., 2007).

In the UK, the ICT (Information Communication Technology) sector has found to have a carbon footprint similar to that of the aviation industry as revealed by a report - An Inefficient Truth by Global Action Plan with guidance from the Environmental IT Leadership Team (EILT) (2007). Moreover, the growth in carbon emission is being exacerbated by Government policies requiring higher levels 
of data to be stored (Global Action Plan, 2007). This survey report also shows that ICT equipments have accounted for 3$4 \%$ of the world's carbon emissions, and $10 \%$ of the UK energy bill. The energy consumption of an average server has approximately the same annual carbon footprint as an SUV doing 15 miles per gallon!

Therefore, it is necessary to focus on the carbon footprint of the data centers in the ICT sector and our research will do just that at this stage. The accountability of producers, consumers, and the manufacturers of the server equipments on carbon emission will also be studied in our research.

\section{LITERATURE REVIEW}

There are a fair amount of researches linking carbon pollution to geographic origins in the current literature with the earliest research by Mark A. Ridgley (1996). He believes that "the distribution of burdens corresponding to GHG reduction should be determined on the basis of equity...", and uses a multicriterion methodology to determine the accountability for GHG emission of each of the specified 11 major world regions. He also takes into account many factors such as culpability and equity, political history of the country, liability of the country, economic well-being of the country, and the 'Ability To Pay' (ATP) (i.e. A nation's wealth and the well-being of its citizens).

There are several accountability models in the current literature that discuss responsibility sharing and burdensharing schemes or models for the general trading industries. Some argue that carbon emission responsibility should be on the producer and some reckon that consumers should be responsible. Regardless of who should be responsible, the goal towards mitigation of global warming should be a priority. Hence, one of the main objectives of our research is to find out who should be responsible for the carbon emission from data centers running and utilizing Internet servers. This helps in the combat against global warming and maintains sustainability in the ICT sector. We will discuss current accountability models proposed for the general trade industries in the next section.

\section{A. Carbon Embodied in Manufactured Products}

Carbon Leakage is a phenomenon whereby $\mathrm{CO}_{2}$ emission is not accounted for by any parties in the chain of production to end consumption. It usually occurs when one or more of the countries involved in the trade are not participants of the Kyoto Protocol. It is also one of the problems from applying 'territorial approach', thus undermining the effects of combating global warming (Ferng, 2003), as global $\mathrm{CO}_{2}$ emissions might not be reduced as expected, and could even increased as a result from non-participating countries of the Kyoto Protocol (Wyckoff \& Roop, 1994).

In the light of the critical relationship between international trade and global warming combat, many studies have attempted to estimate the embodied carbon of international trade (e.g. Wyckoff \& Roop, 1994; Schaeffer \& Leal de Sa', 1996; Battjes et al., 1998; Lenzen, 1998; Kondo et al., 1998; Machado et al., 2001; Munksgaard \& Pedersen, 2001; Ferng, 2003). Munksgaard \& Pedersen (2001) further discussed the ensuing difficulty in reducing domestic $\mathrm{CO}_{2}$ emissions for an open economy with great net carbon exports. Kondo et al. (1998) also suggested allocating the responsibility of $\mathrm{CO}_{2}$ emissions accordingly using a combination of the consumer-benefit and producer-benefit principles. A major difference between their (Kondo et al., 1998; Bullard \& Herendeen, 1975; Islam \& Morison, 1992) producer-benefit principle and of Ferng (2003) is that it includes the induced $\mathrm{CO}_{2}$ emissions in foreign countries for delivering the intermediate inputs required by the production sectors of the analyzed countries.

\section{B. Carbon Sequestration}

In addition, some studies have estimated the amounts of carbon sequestrated by forest ecosystems (e.g. Eriksson, 1991; Winjum et al., 1992; Dixon et al., 1994; Folke et al., 1997; Jansson \& Nohrstedt, 2001), and by other ecosystems such as wetlands and lakes (Eriksson, 1991; Jansson \& Nohrstedt, 2001; Ferng, 2003). The effectiveness of carbon sequestration of forests depends on the types of forests with different species of plants and the location of the forest (Ferng, 2003). Generally, forests in tropical latitudes have a higher carbon sequestration capability than that in temporal latitudes, followed by forests in boreal latitudes (Winjum et al., 1992; Ferng, 2003).

Carbon sink is an effective method to mitigate carbon emission into the environment, and helps to encourage reforestation and maintain existing forest ecosystems and wetlands. However, it is not a feasible long term plan for mitigating environmental degradation due to the facts that forests and wetlands take up lots of land and their carbon sequestration capability will decrease significantly throughout the years (van den Bergh \& Verbruggen, 1999; Ferng, 2003). Thus, it is more feasible for both producers and consumers to be more responsible through reducing excessive carbon emissions into the environment by using renewable energy whenever possible against the battle of global warming.

In the previous two sections, we have talked about the basic concepts of accountability and methods to help in the combat against climate change. We will now explore various accountability models and the work which has been currently undertaken in this area.

\section{Producer Accountability Model}

There are a few producer accountability models worth mentioning which includes the Production Accounting Method, IPCC approach, Territorial approach, and Geographical approach in the current literature.

\section{1) Production Accounting Method}

The production accounting principle is the principle most widely recognised in the current system of the Kyoto Protocol where the producers of goods and services are solely responsible for the $\mathrm{CO}_{2}$ emissions from the production process in the origin country. The model considers $\mathrm{CO}_{2}$ emissions from domestic production including production for exports to other countries. The drawback of this method is the lack of recognition between exports and domestic consumptions. One of the examples in Munksgaard et al. (2001) research of Danish GHG emissions has specifically 
shown that this method is flawed as Denmark has a lower $\mathrm{CO}_{2}$ emissions level when using the consumption accounting principle.

\section{2) IPCC Approach}

IPCC approach also commonly referred to as geographical approach and territorial approach (Bastianoni, 2004), incorporates the reference approach and sectoral approach (Ferng, 2003); where the model considers $\mathrm{CO}_{2}$ emissions produced in each sector of the nation within the country boundaries. The model does not consider $\mathrm{CO}_{2}$ emissions indirectly related to the chain of production process, such as transportation and consumption. This method is similar to the polluter-pay principle where responsibility is assigned to direct emitters (Ferng, 2003). It only considers the amount of 'national direct $\mathrm{CO}_{2}$ emissions' which will likely lead to the problem of 'carbon leakage' (Ferng, 2003), and not attaining the expected results of the combat against carbon reduction globally.

This is thought to be an inefficacious and unfair system of $\mathrm{CO}_{2}$ emission accountability method and is especially evident in the case where a country has to be responsible for the goods that it has neither produced nor consumed, when the only reason for it to be responsible is its geographical location which is between the production country and the consumption country, where the goods has to be transit.

Another disadvantage is that it uses a standardized method at a local level, and the emission data are mostly based on estimates where default emission factors are recommended whenever precise national data are unavailable; although IPCC presents a rich database whenever possible. Thus, this approach has a high degree of uncertainty due to the lack of appropriate and accurate estimation models and the variability in the time and space. This high uncertainty in the emission inventories level would in turn deter the process of cost reduction strategies for reducing global GHG emissions.

In the following section, we will look at consumer accountability approaches which are directly opposite to the producer accountability approaches mentioned earlier.

\section{Consumer Accountability Model}

Consumer accountability models include the Consumption Accounting Method, Benefit principle and Ecological Deficit principle, which hold the consumers responsible for the carbon emission.

\section{1) Consumption Accounting Method}

The consumption accounting principle suggested that consumers are to be responsible for the $\mathrm{CO}_{2}$ emissions from the production to the final usage of goods and services regardless of whether they are imported or domestically produced. This model considers $\mathrm{CO}_{2}$ emissions caused by domestic consumption including emissions embodied in imports.

The main drawback of consumption accounting method is the consumer inability of influence on the technologies and fuels used in the production of imported commodities in the origin country.

2) Benefit Principle
The benefit principle is different to the IPCC approach and is similar to the consumption principle of Munksgaard (2001) as it recognizes the driving forces behind the production activities that emit pollutants and assigns the responsibility to the force-drivers. It argues that production and consumption activities are both responsible for the $\mathrm{CO}_{2}$ emissions and not confined to the area where only production and consumption activities occur. This model calculates the 'national responsible $\mathrm{CO}_{2}$ emissions' for the responsibility sharing of the reduction of global GHG emissions.

The criteria to be considered in this model are the goods and services produced and consumed, directly and indirectly in the residential consumption of a defined country (Ferng, 2003). The term 'defined country' refers to a country who is responsible for the amount of $\mathrm{CO}_{2}$ emissions from the production of commodities required directly and indirectly for residential consumption, regardless of where the production activities is held; and also from the domestic consumption of energy products (Ferng, 2003).

There are two subcategories in the benefit principle, namely the 'consumption-benefit principle' and the 'production-benefit principle'.

Under the consumption-benefit principle, a defined country is responsible for $\mathrm{CO}_{2}$ emissions from the production of goods and services regardless of where the production activities are located for supporting its domestic residential consumption; as well for the $\mathrm{CO}_{2}$ emissions from its domestic residential consumption of energy products.

Whereas, under the production-benefit principle, the subjects to be considered are the goods and services produced by the production sectors located in the defined country; and also the imported goods and services required directly and indirectly for the transportation of commodities into the production facilities in the defined country (Ferng, 2003). Therefore, the defined country is responsible for the $\mathrm{CO}_{2}$ emissions produced domestically in the country for local consumption and exports; as well as for $\mathrm{CO}_{2}$ emissions associated with its imported production inputs; and from the logistics of the raw commodities to the production facilities (Ferng, 2003).

One of the advantages of benefit principle includes the discouragement of 'carbon leakage', and halts the process of environmental degradation from $\mathrm{CO}_{2}$ emissions in both developed and developing countries (Ferng, 2003). It is more beneficial to developing countries than the IPCC approach when the consumption-benefit principle is applied as it excludes the amount of $\mathrm{CO}_{2}$ emissions from exports productions and would hopefully encourage more participation from developing countries.

The disadvantage of benefit principle is the possible double counting in the calculation of $\mathrm{CO}_{2}$ emissions in countries $\mathrm{CO}_{2}$ emissions inventory.

\section{3) Ecological Deficit}

Ecological deficit principle stems from the concept of 'Ecological Footprint Analysis' initiated by Rees \& Wackernagel in the early 1990s (1996; Ferng, 2003). The Ecological Footprint Analysis is the estimation of resources and carbon sinks used or required by consumption and 
production activities, and expresses these requirements in area units (Ferng, 2003; Wackernagel \& Rees, 1996). This analysis incorporates the concept of both 'consumptionbenefit' and 'production-benefit' principles.

The ecological footprint analysis estimates the 'ecological deficit' of the country itself. Ecological deficit is the excessive demand or the requirement of additional productive areas to support for local consumption and production beyond what can be offered by the country itself. It serves as a rough index of self-sufficiency and differs from the 'carrying capacity analysis' as it explicitly considers the trans-boundary environmental pressures of the globalization of world economies (Ferng, 2003).

One of the benefits of Ecological Deficit principle include the ability to find out if a country domestic assimilation capacity has been overtaxed. Due to the idea and context of 'self-sufficiency' in the ecological deficit model, it recognizes the carbon sink capacity of ecosystems; thus bringing awareness to the harmful deforestation activities globally, especially of tropical forests in developing countries (Vojnovic, 1995; Ferng, 2003). This accounting method will be beneficial to developing countries with massive forest areas as carbon credits, which will in turn help to halt the widespread of deforestation activities in these countries, enhancing and maintaining carbon sinks on a global scale. This will hopefully encourage higher participation rate from developing countries in the global combat of $\mathrm{CO}_{2}$ emissions reduction.

Now that we have covered the basic concepts of accountability and the three major accountability approaches, we now move on and discuss Input Output Analysis which forms the key component in these accountability models.

\section{E. Input Output Analysis}

IO analysis is useful in accounting for GHG emissions and pollutants produced in the whole chain of production process of a particular good including the imported inputs used in the production process (Wyckoff \& Roop, 1994). It is a suitable tool for assessment of resources and pollutants embodiments in goods and services on a macroeconomic scale (Lenzen, 2006). 'The purpose of the IO analysis is to trace these interactions and to examine how policy alternatives modify the two-way flow process' (Forssell \& Polenske, 1998).

The IO analysis method has many functions and is often used for the approximation of energy and estimation of anthropogenic $\mathrm{CO}_{2}$ emissions at the stages of production and consumption as well as embodied energy and carbon from international trade of products. It is also used in assessment of the amount of carbon leakage, allocation of responsible environmental pressures to a region's industries in terms of selective principle of territorial responsibility and the proposed benefit principle herein, as well as in the estimation of $\mathrm{CO}_{2}$ emissions from fossil fuel combustion. The major difference in the many versions of IO analysis in the current literature is the monetary versus the hybrid units of technical coefficients matrix (Ferng, 2003).

The hybrid version of the IO analysis has claimed to prevent the violation of energy conservation condition that might occur when monetary transaction tables are used in the estimation of embodied energy and energy intensity of products. The row entries corresponding to the energy sectors in an IO table are measured in physical units which consist of energy consumed as fuels and as raw materials, and the estimated figures are the amounts of energy/carbon embodied in products under the hybrid method (Ferng, 2003).

Whilst the monetary method estimates $\mathrm{CO}_{2}$ emissions by combining monetary coefficients with information regarding the primary fossil fuels combusted at the stages of production and consumption and the coefficients of $\mathrm{CO}_{2}$ emissions (Ferng, 2003). In this method, the amount of energy combusted or $\mathrm{CO}_{2}$ emissions at stages of production and consumption can be estimated separately. The place, domestic areas or foreign countries where the energy combustion occurred and $\mathrm{CO}_{2}$ emitted can be distinguished under this method. Although the monetary method might violate the conservation condition, it could also have correct estimates when applied to the final demand of the base case from which the model is initially derived (Miller \& Blair, 1985; Ferng, 2003).

In the next section, we will present to you who should be responsible for the carbon emitted into the environment producers or consumers.

\section{F. Producer OR Consumer Responsibility}

Producers are the direct emitters of $\mathrm{CO}_{2}$ and are usually expected to be responsible for all the pollutants emitted into the environment as there are economics and monetary benefits associated in the whole chain of production.

Consumers on the other hand are also expected to be responsible for their 'actions' as it is believed that "consumption is the sole end purpose of all production" (Adam Smith; Lenzen, 1998). The consumption of products has also social and economic benefits to the consumers. Monetary benefit is possible in some cases where consumers are also the producers of products and/or services.

Since production benefit in income generation and consumption benefit in living standards are the two major impetus of the contribution to the degradation of the environment, the excessive $\mathrm{CO}_{2}$ emissions should be shared by both producers and consumers (Ferng, 2003).

However, there are not many studies on the accountability of $\mathrm{CO}_{2}$ emissions for the ICT industry in the literature yet. Therefore, our research aims at identifying the various stakeholders of the ICT industry and the shared responsibility of anthropogenic $\mathrm{CO}_{2}$ emissions that each stakeholder should bear for the operation of data server centers.

\section{RESEARCH ISSUES}

From the literature study that we conducted, we have identified the following problems with emission accountability:

- $\mathrm{CO}_{2}$ Embodiment: How to account for national $\mathrm{CO}_{2}$ emissions for open economises considering the embodiment of $\mathrm{CO}_{2}$ in international trade? 
- International Trade $\& \mathbf{C O}_{2}$ : Is it right to charge a nation for $\mathrm{CO}_{2}$ emissions generated in their space for products or services that are designed for export or for foreigners who are living in other countries?

- Producer vs. Consumer Responsibility: Who should be responsible for emitting $\mathrm{CO}_{2}$ into the atmosphere?

- Right Accounting Principle: Which accounting principle is more appropriate (i.e. consumer accounting vs. producer accounting)? Currently most of the policies are based on producer accountability, why not include consumer accounting principles and study the comparative benefits of each approach?

- Emissions per Consumer: Given consumers are held responsible for emissions, how would you measure the amount of emissions generated per consumer, are they any models that exist to measure this. It is a long and complex process to assign a emission value to a particular product since it is a result of a complex supply chain process (i.e. the process from fetching the raw materials to processing it to final products and to shipping it to the warehouses or retail stores and the fuel consumed by the customer to go and buy the product).

- Carbon Leakage - It is a problem caused by inconsistency of the accountability of GHG emissions on a global scale, specifically carbon emissions by non-participating countries produced for participants of the Kyoto Protocol. A successful outcome can be attained when there is global participation with a burden-sharing scheme that is fair to both developed and developing countries (Ferng, 2003). Thus in this case, we might suggest our own accountability model to correct this 'problem' and the amount of responsibility to be bear by entities involved in the chain of production to end consumption in the case of data centers.

Given the research issues anticipated, we will first identify all determinant factors in $\mathrm{CO}_{2}$ emissions accountability in ICT industry. With the information on hand, we will craft out a scenario with the stakeholders involved and then evaluate the carbon emissions using both consumer and producer accountability models. We will then identify the approach that is more beneficial in the combat against carbon mitigation and proceed with the development of an accountability model for the ICT industry. We will also measure the associated GHG emissions from operating the data centers and discourage any carbon leakage issues in these areas whenever possible. We hope to bring the issue on the balance of carbon sink and sequestration to attention as well.

\section{SIGNIFICANCE OF RESEARCH}

\section{Scientific Significance}

- One of the first studies to do a comparative analysis on the impact of consumer benefit principle versus producer benefit principle for the $\mathrm{CO}_{2}$ emissions generated by the operation of data centers.

- This research will provide new literature in the area of accountability in carbon emissions, sustainability of data centers, manufacturing costs and end pricing, etc.

- Development of new framework for accountability for maintaining data server centers in ICT industry.

Socio-Economic Significance

- As the world is trying very hard and working jointly against mitigating carbon emission into the environment to provide a better environment, more carbon-intensive industries will be included into climate treaties globally. With the latest climate change policies in act, this research on accountability will address those concerns such as who is responsible for carbon emissions, which is a fair accounting principle i.e. consumer vs. producer benefit principle, etc.

- The output of this research would have policy implications and could be used by Governments worldwide in deciding which accounting principle to adopt for $\mathrm{CO}_{2}$ emissions by ICT industry.

The outcome of this research would benefit companies in ICT sector in their employment of better business strategies and business sustainability, and also reduction of $\mathrm{CO}_{2}$ emission into the environment.

\section{CONCLUSION}

We have aimed to develop an efficient and effective just $\mathrm{CO}_{2}$ emission accountability model for the ICT industry to assist companies in doing their part to cope with the recent climate change policies under the Kyoto Protocol and COP15 treaty. This research will first determine the factors of influence in the ICT industry and then focus on the development of the accountability model for the industry. Evaluations will be made on the newly developed accountability model against the current producer and consumer accountability approaches. Suggestions for future works along this path and area will also be mentioned.

\section{REFERENCES}

[1] Australian Government, Department of Climate Change (n.d.), 'Reducing Australia's emissions - Think Change', http://www.climatechange.gov.au/government/reduce.aspx, Retrieved: Jan 08, 2010.

[2] Bastianoni, S., Pulselli, F. M., Tiezzi, E., 2004, 'News and Views: The problem of assigning responsibility for greenhouse gas emissions', Energy Policy 2004, vol 49, pp. 253-257.

[3] Brill, K. G., 2007, 'White Paper - The Invisible Crisis in the Data Center: The Economic Meltdown of Moore's Law', Retrieved: July 2010.

[4] Brouwer, R., Brander, L., Van Beukering, P., 2008, 'A convenient truth: air travel passengers' willingness to pay to offset their $\mathrm{CO} 2$ emissions', Climatic Change 2008, Springer, pp. 299-313.

[5] Brueckner, J.K., Zhange, A., 2009, 'Airline Emission Charges: Effects on Airfares, Service Quality, and Aircraft Design', CESIFO Working Paper NO. 2547 February 2009. 
[6] Ferng, J. J., 2003, 'Analysis: Allocating the responsibility of $\mathrm{CO}_{2}$ over-emissions from the perspectives of benefit principles and ecological deficit', Ecological Economics 2003, vol 46, pp. 121-141.

[7] Forssell, O., Polenske, K. R., 1998, 'Introduction: Input-Output and the Environment', Economic Systems Research, Retrieved: March 9, 2010.

[8] Gossling, S., Broderick, J., Upham, P., Ceron, JP., Dubois, G., Peeters, P., Strasdas, W., 2007, 'Voluntary Carbon Offsetting Schemes for Aviation: Efficiency, Credibility and Sustainable Tourism', Journal of Sustainable Tourism (2007), vol 15, no. 3, pp. 223-248.

[9] Gupta, S., Bhandari, P. M., 1998, 'An effective criterion for $\mathrm{CO}_{2}$ emissions', Energy Policy 1999, vol 27, pp. 727-736.

[10] Jacobs, I. S. \& Bean, C. P., "Fine particles, thin films and exchange anisotropy," in Magnetism, vol. III, G. T. Rado and H. Suhl, Eds. New York: Academic, 1963, pp. 271-350.

[11] Lenzen, M., 2006, 'Primary energy and greenhouse gases embodied in Australian final consumption: input-output analysis', Energy Policy1998, vol 26, no. 6, pp. 495-506.

[12] Minister for Climate Change and Water (n.d.), 'A New Target For Reducing Australia's Carbon Pollution, http://www.climatechange.gov.au/en/government/international/intern ational-climate-change-negotiations/copenhagen-accord.aspx, Retrieved: Jan 08, 2010.

[13] Munksgaard, J., Pedersen, K. A., 1999, ' $\mathrm{CO}_{2}$ accounts for open economies: producer or consumer responsibility?', Energy Policy 2001, vol 29, pp. 327-334.

[14] Neumayer, E., 2004, 'National carbon dioxide emissions: geography matters', LSE Research Online, vol 36 (1), pp. 33-40.

[15] Proops, J. L. R., Atkinson, G., Schlotheim, B. F.v., Simon, S., 1999, 'Analysis: International trade and the sustainability footprint: a practical criterion for its assessment', Energy Policy 1999, vol 28, pp. 75-97.

[16] Qantas Airways Limited, 2008, 'Developing a more sustainable Australian Aviation Industry : Submission to the Australian Government Carbon Pollution Reduction Scheme Green Paper September 2008', Retrieved: Oct 20, 2009.

[17] Ridgley, A. M., 1996, 'Fair sharing of greenhouse gas burdens', Energy Policy, vol 24, no. 6, pp. 517-529.

[18] Wyckoff, A. W., Roop, J. M., 1994, 'The embodiment of carbon in imports of manufactured products - Implications for international agreements on greenhouse gas emissions', Butterworth-Heinemann Ltd.

[19] Australian Government, 2008, 'Carbon Pollution Reduction Scheme - Australia's low pollution future' White Paper Fact Sheets, December 2007, www.climatechange.gov.au, Retrieved: July 08, 2009.

[20] Australian Government, 2008, 'Carbon Pollution Reduction Scheme The benefits of early action', White Paper Fact Sheets, December 2008, www.climatechange.gov.au, Retrieved: July 08, 2009.

[21] Australian Government, 2008, 'Carbon Pollution Reduction Scheme - 10 key commitment', White Paper Fact Sheets, July 2008, www.climatechange.gov.au, Retrieved: July 08, 2009.

[22] Australian Government, 2008, 'Emission Trading - How it works', December 2008, www.climatechange.gov.au, Retrieved: July 08, 2009.

[23] Australian Government, 2008, 'Scheme Coverage', Fact Sheet, December 2008, www.climatechange.gov.au, Retrieved: July 08, 2009.

[24] Bataller, M., Tonero, A. \& Micó, E., 2006, 'CO2 Prices, Energy and Weather', Valencia, Spain.

[25] Benz, E. \& Truck, S., 2008, 'Modeling the price dynamics of CO2 emission allowances', Energy Economics 31(2009), pp. 4-15, July 16, 2008.
[26] Burstein, F., \& Gregor, S., 1999, 'The Systems Development or Engineering Approach to Research in Information Systems: An Action Research Perspective', in The 10th Australasian Conference on Information Systems, P. Yoong, Ed. School of Communications and Information Management, Victoria University of Wellington, New Zealand, 1999, pp. 122-134.

[27] Convery, F. \& Redmond, L., 2007, 'Market and Price Developments in the European Union Emissions Trading Scheme', Review of Environmental Economics and Policy, vol 1, iss 1, winter 2007, pp. 88-111.

[28] Department of Climate Change (n.d), 'Fact Sheet - Implementing KYOTO Protocol in Australia', www.climatechange.gov.au, Retrieved: July 08, 2009

[29] Energy Information Administration (EIA), 2008, 'Greenhouse gases, Climate Change and Energy', DOE/EA X012, May 2008, www.eia.doe.gov, Retrieved: July 08, 2009.

[30] Galliers, R., 1992, 'Choosing Information Systems Research Approaches', Information Systems Research: Issues, Methods and Practical Guidelines, Blackwell Scientific, pp. 144-162.

[31] Hodgkinson, D., Turner, M., Stegich, S., Margo, R. \& McGinn, L., 2009, 'Aviation and Climate Change - Law \& Policy', Newsletter, vol 2 , iss 1 .

[32] Holtsmark, B., Maestad, O., 2002, 'Emissions trading under the Kyoto Protocol : Effects on fossil fuel markets under alternative regimes', Energy Policy 30, pp. 207-218.

[33] International Emission Trading Association (IETA), 2006, 'State and Trends of the Carbon Market 2006', November 2006, http://epa.gov/highgwp/electricpowersf6/documents/conf06_capoor.pdf, San Antonio, Retrieved: July 08, 2009 .

[34] Lowrey, C., 2006, 'A changing environment', FOW Energy, Spring 2006, pp 24-26.

[35] Milmo, D. 2009, 'Australia calls for Aviation to be part of climate change treaty - Proposal brings worldwide carbon tax for airline passengers http://www.guardian.co.uk/business/2009/jun/14/airlines-emissio, Sunday, 14 June 2009 15.41 BST, Retrieved: September 14, 2009

[36] Nunamaker Jr., J., \& Chen, M., 1990, 'Systems development in information systems research', in System Sciences, Proceedings of the Twenty-Third Annual Hawaii International Conference on, pp. 631-640, vol.3.

[37] Springer, U., 2002, 'The market for tradable GHG permits under the Kyoto Protocol: A survey of model studies', Energy economics 25 (2003), pp. 527-551.

[38] Springer, U., Varilek, M., 2003, 'Estimating the price of tradable permits for greenhouse gas emissions in 2008-12', Energy Policy 32 (2004), pp. 611-621.

[39] Weyant, J., Davidson, O., Dowlatabadi, H., Edmonds, J., Grubb, M., Parson, E.A., Richels, R., Rotmans, J., Shukla, P.R., Tol, R.S.J., Cline, W., \& Fankhauser, S., 'Integrated Assessment of Climate Change: An Overview and Comparison of Approaches and Results', In: Intergovernmental Panel on Climate Change (IPCC), 1996, In: Bruce, J.P., Lee, H., Haites, E.F. (Eds.), Climate Change 1995 Economic and Social Dimensions of Climate Change, Cambridge University Press, Cambridge, pp. 367-396.

[40] Global Action Plan, 2007, ' Inefficient ICT sector's carbon emissions set to surpass aviation industry - December 2007, http://www.globalactionplan.org.uk, Retrieved: July, 2010.

[41] Chase, J. S. \& Doyle, R. P., n.d., ' Balance of Power: Energy Management for Server Clusters', Retrieved: July, 2010

[42] Bryce, R., 2000, ' Power Struggle - Interactive Week', http://www.zdnet.com/intweek/stories/news/0,4164,2666038,00.html, Retrieved: July, 2010.

[43] Vahdat, A., Lebreck, A., \& Ellis, C. S., n.d., 'Every Joule is Precious: The Case for Revisiting Operating System Design for Energy Efficiency’, Retrieved: July, 2010. 